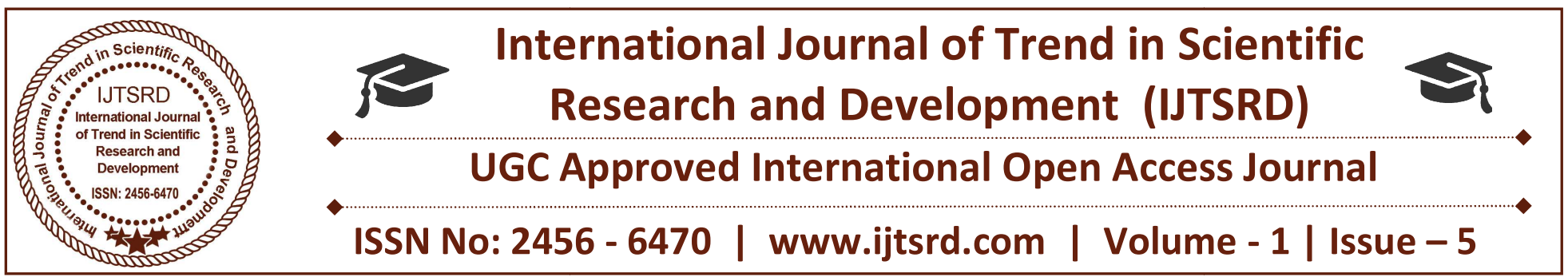

\title{
Alternative Low Cost Building Materials On Beams
}

\author{
G Khaja \\ Department of Civil Engineering, \\ SVR Engineering College, \\ Nandyal
}

\author{
P Sai \\ Department of Civil Engineering, \\ SVR Engineering College, Nandya
}

\author{
K Siva Sankar \\ Department of Civil Engineering, \\ SVR Engineering College, \\ Nandyal
}

\begin{abstract}
Today, transfer of waste material is an incredible issue and it gets to be hard to discover common assets because of their extreme abuse. Utilization of waste materials as development materials has various advantages, for example, diminishment in cost, saving in energy, and protection of environment. coconut shell is a waste material which can be a substitute for aggregate. Along these lines, the primary goal of this anticipate is to empower the utilization of coconut shell as a development material and to get ready lightweight concrete by utilizing coconut shell as coarse aggregate. In this anticipate, exploratory study has been done on characteristic strength of M35 concrete with substitution of $15 \%$ and $30 \%$ of coarse aggregate by coconut shell. Also an attempt has been made to examine the suitability of replacing the $20 \%$ of flyash with cement and simultaneously by replacing $15 \%$ and $30 \%$ of coconut shell as coarse aggregate for concrete of grade M35. The results found were comparable with that of Traditional mix.
\end{abstract}

Keywords: Concrete, Aggregate, Coconut Shell, Flyash, Strength

\section{INTRODUCTION}

\subsection{GENERAL}

Concrete is the extensively used number one basic material on the planet today. The enthusiasm to create the light weight material has been the subject of study that has tested researchers and specialists alike. The test in making a lightweight concrete is diminishing the density while keeping up quality and without unfavorably impacting cost bringing new aggregates in with the general mish-mash outline is a typical approach to bring down a concrete thickness. Ordinary mix contains four parts, binder, smashed stone, sand and water. The pulverized stone and sand are the parts that are for the most part supplanted with lightweight aggregates. Lightweight concrete is generally made by joining characteristic or manufactured lightweight aggregate. A portion of the lightweight aggregate utilized for light weight concrete creations

Concrete is a manufactured composite, comprises of fixings, for example, cement and water. Today, because of headway of foundation in both creating and created nations, the usage of cement has been extending at a higher rate. The cost of development material is expanding orderly on account of popularity and lack of crude materials. growing interest of concrete causes exhaustion of aggregate stores, ecological corruption and natural lopsidedness.

In perspective of this test, analysts all through the world have been examining method for supplanting aggregate to make development supportable and temperate. Distinctive analysts have inspected the use of coconut shell and their backup in auxiliary building improvement. Coconut shell is a copiously accessible agricultural waste from neighbourhood coconut business ventures, so its transfer is a major issue for nearby environment. In this way, these squanders can be utilized as substitution material as a part of the 
development business. This will decrease the cost of development materials and take care of the issue of transfer of squanders. The effect resistance, dampness holding and water engrossing limit of coconut shells are more contrasted with ordinary aggregate. Thickness of coconut shells are inside as far as possible for lightweight aggregate, advance increasingly the strength properties of coconut shell aggregate are similar to other conventional lightweight concrete, so light weight concrete can be set by using coconut shell as coarse aggregate. These optional lightweight materials are grasped for non load bearing dividers and non basic floors in building.

\subsection{MATERIALS:}

The constituent materials used in this anticipate were gotten from nearby sources and these were normal portland concrete (O.P.C), Fly ash as halfway substitution of cement, sand as fine aggregate, pulverized stone and C.S. both as C.A. consumable water was utilized for blending and curing.

I. binder: Ordinary Portland cement (O.P.C) 53 Grade was used conforming with IS 12269-1989

II. Fine aggregate: canal sand was utilized as fine aggregate agreeing to zone III according to IS 3831970

III. Coarse Aggregate: Crushed stone was utilized as coarse aggregate of size $20 \mathrm{~mm}$. conforming with IS $2386-1963$

IV. Fly Ash and Sun Dried Coconut Shell was utilized as an alternative(optional) materials.

\subsection{OBJECTIVES OF THE STUDY:}

On the off chance that basic Light Weight Concrete can be created from coconut shells, which is locally open in wealth, it would be an advancement accomplishment for the nearby development undertakings. Therefore, the fundamental target of this exploration is to choose the likelihood of utilizing strong waste coconut shells as coarse aggregate for auxiliary Light weight concrete. To study the properties of coconut shells, similarity of coconut shells with cement and to create coconut shell aggregate concrete with 28 day compressive quality more than 20

$\mathrm{N} / \mathrm{mm} 2$.
To study the quality properties of cement in substitution of coarse aggregate .

$>$ To study the quality properties of cement in substitution of coarse aggregate and supplanting of flyash with concrete.

$>$ To study the concept of compressive and split tensile strengths.

To find efficient solution for high cost development material.

To plan lightweight concrete by utilizing coconut shell as course aggregate.

\subsection{SCOPE OF THE WORK:}

The point of this study is to study the utility and profitability of coconut shells as a coarse aggregate as a contrasting option to characteristic aggregate in cement.

1) This trail work was held to acquire the quality of halfway supplanting of concrete with flyash and smashed stone with coconut shells.

2) In this test two sources of substitution materials are utilized i.e.; coconut shell and flyash.

3) The test is led for long term curing to know quality changes

4) Test like compressive quality, split elasticity and flexural quality are directed by varying the (\%ge) of flyash and coconut shell.

\section{REVIEW OF LITERATURE:}

Recent works done in partial replacement of cement with flyash and crushed gravel is replaced with coconut shell separately.

Vishwas p. kulkarni and sanjay kumar (international journal of engineering and innovative technology) june2013 [2] in this they concentrated on that aggregates gives volume with ease, including $66 \%$ to $78 \%$ of concrete. Customary coarse aggregate in particular rock and fine aggregate is sand in cement will be utilized as control. Whereas, normal material is coconut shell as coarse aggregate will be examine to supplant the aggregate in concrete. In this study three distinctive cement blends with various the mix of regular material substance in particular $10 \%, 20 \%$, $30 \%$. Three example orchestrated every cement blends.

Amarnath Yerramalaa (international journal of engineering inventions) October2012 [4] Examined the quality of coconut shell substitution and 
unmistakable study the vehicle properties with coconut shells as coarse aggregate substitution. They presumed that, by expansion in coconut shell rate, diminished the density of concrete and with C.S\% expanded the 7 days quality pick up additionally expanded with comparing 28 days curing quality.

Sreenivasulu dandagala,Praveen $\mathbf{k}$, anil kumar $\mathbf{P}$ (nationwide consultation of green production and technology for sustainable outlook) 2014 Compared the normal concrete with coconut shell. Coconut shell can be used as full substitution of smashed grainite or ordinary aggregate in cement development. It was watched that coconut shell concrete indicating $65 \%$ of compressive quality to that of ordinary concrete. There is not required to test the CS previous to use an aggregate except for water assimilation. Coconut shell exhibit more confrontation beside crushing.

Manider kaur,manpreet kaur (international journal of applied engineering research ) 2012 This is a evaluation on consumption of C.S. as course aggregate in mass cement Compressive quality of the cement declines as the rate of the C.S. increments in the two blend propottions. For a situation, concrete got from CCS displayed a higher compressive quality than palm kernel shell. Comes about likewise showed that 30 to $40 \%$ cost diminishment for concrete created from C.S. what's more, palm kernal shell individually. (coconut shell is more reasonable) when utilized as substitute for ordinary aggregate in concrete generation.

\section{METHODOLOGY AND TESTS}

\subsection{METHODOLOGY:}

The project work requires preparatory examinations in a method way

1. Selection of kind of evaluation of blend, blend outline by a fitting procedure, trial blend, last blend degrees.

2. Estimate the measure of concrete required for the entire work.

3. Estimating the amount of binder, fine aggregate, coarse aggregate, coconut shells, Flyash required for the undertaking work.

4. Testing the property of cement, fine aggregate, coarse aggregate, Flyash and coconut shells.

5. Testing the cubes, cylinders, and beams by utilizing pressure testing machine and loading frame.

\subsection{INITIAL TESTS CONDUCTED}

\subsubsection{Cement:}

The cement must progress suitable strength. For this research 53grade ordinary Portland cement, compatible to IS 12269-1989 was used. It must signify the suitable rheological performance.

\begin{tabular}{|l|l|l|}
\hline $\begin{array}{l}\text { SI. } \\
\text { no }\end{array}$ & Physical assets & $\begin{array}{l}\text { Experimental } \\
\text { results }\end{array}$ \\
\hline $\mathbf{1}$ & Standard consistency & $30 \%$ \\
\hline $\mathbf{2}$ & Specific gravity & 3.10 \\
\hline $\mathbf{3}$ & Initial setting time & 45 minutes \\
\hline $\mathbf{4}$ & Final setting time & 280 minutes \\
\hline
\end{tabular}

\subsubsection{Fine aggregate:}

For fine aggregate canal sand was used, comparable to IS 383-1970. To remove imported material, to use air dried sand, sieved, and earlier to mixing.

\begin{tabular}{|l|l|l|}
\hline Sl.no & Physical assets & Experimental \\
\hline $\mathbf{1}$ & Specific gravity & 2.6 \\
\hline $\mathbf{2}$ & Bulk density for lose FA & $1460 \mathrm{~kg} / \mathrm{m}^{3}$ \\
\hline $\mathbf{3}$ & $\begin{array}{l}\text { Bulk density for } \\
\text { compacted FA }\end{array}$ & $1642 \mathrm{~kg} / \mathrm{m}^{3}$ \\
\hline
\end{tabular}

\subsubsection{Course aggregate:}

In present investigation, broken or crushed stones with aggregate size $20 \mathrm{~mm}$ are considered. The experimental results are tabulated bellow confirming with IS 2386-1963 codes.

\begin{tabular}{|l|l|l|}
\hline SI.no & Physical assets & Experimental \\
\hline $\mathbf{1}$ & Specific gravity & 2.76 \\
\hline $\mathbf{2}$ & Bulk density for lose FA & $1471 \mathrm{~kg} / \mathrm{m}^{3}$ \\
\hline $\mathbf{3}$ & Bulk density for & $1600 \mathrm{~kg} / \mathrm{m}^{3}$ \\
\hline
\end{tabular}

\subsubsection{IMPACT TEST:}

Impact is the very important test for coarser materials. Toughness is the property of a material to resist impact. it is characterised by the energy absorbed before failure. 


\begin{tabular}{|l|l|l|}
\hline SI.no & Physical assets & Experimental \\
\hline $\mathbf{1}$ & Crushed gravel & $23.18 \%$ \\
\hline $\mathbf{2}$ & Coconut shell & $14.87 \%$ \\
\hline
\end{tabular}

\subsubsection{SLUMP TEST:}

Slump test is one of the principle elements in mix design. This test was produced by champ man in the United States in 1913. This test gives a thought regarding constancy mix and by implication measures the workability of the concrete mix taken.

Contingent upon the droop values the cement can be characterized into various categories. Workability is characterized as simplicity and homogeneity with which cement can be blended. It is the property which relies on upon particular states of situation. A portion of the vital components that affect the workability of concrete are

a. Relative amounts of paste and aggregates.

b. Max. size and reviewing of aggregates

c. Shape and surface attributes of aggregates

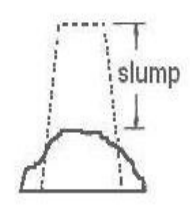

Collapse

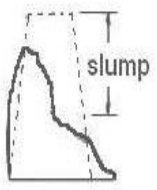

Shear Types of slump

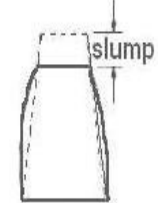

True slump
Variation of slump values with percentage of C.S and with \%C.S $+20 \%$ F.A replacement .

For $0 \%$ Coconut Shell $=85 \mathrm{~mm}$ Slump

For $15 \%$ Coconut Shell $=70 \mathrm{~mm}$ Slump

For $30 \%$ Coconut Shell $=76 \mathrm{~m}$ Slump

For $15 \%$ C.S And 20\% Flyash $=80 \mathrm{~mm}$ Slump

For 30\% C.S And 20\% Flyash $=82 \mathrm{~mm}$ Slump

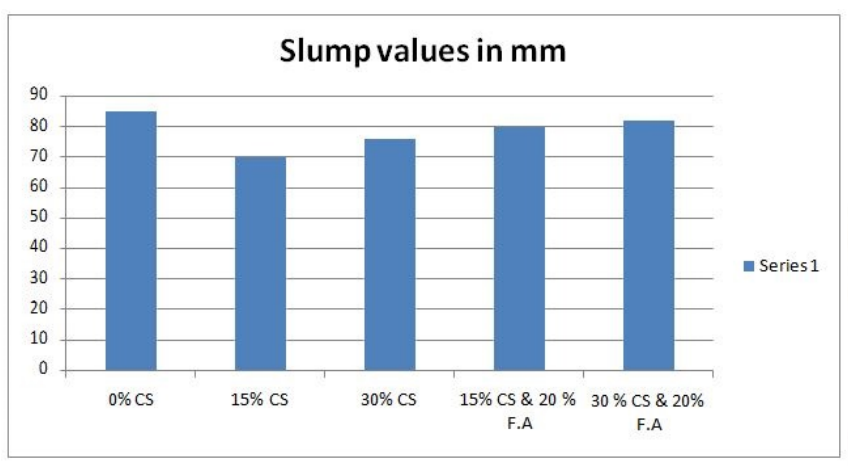

Graph : slump values

\section{TESTS ON HARDENED CONCRETE}

\section{OVERVIEW OF TESTS CONDUCTED}

After the completion of casting of the required specimens, the specimens are kept for curing of 7 days and 28 days. The variations of the strength for the casted specimens are plotted in the graph.

The tests which I have conducted:

1) Compression strength test

2) Tensile strength test

3) FlexuralStrength test on PCC

4) FlexuralStrength test on RCC

\subsection{COMPRESSION STRENGTH TEST:-}

Compressive quality is characterized a most great resistance of a concrete shape to pivotal stacking. Specimen of size $150 \mathrm{~mm}$ x $150 \mathrm{~mm}$ x $150 \mathrm{~mm}$ were utilized for pressure testing for every cluster of mix. Testing of examples was completed at the earliest opportunity subsequent to curing. The estimations of example measurements were taken before the testing. Cleaned and surface dried specimen was placed in the testing machine. Most extreme burden at which the specimen fizzled was recorded and compression strength was calculated.

Equation to find the compression strength: $\mathrm{fcu}=\mathrm{P} / \mathrm{A}$

Where, $\mathrm{P}=$ Failure Load In Compression (KN) $\mathrm{A}=$ Load Area Of The Cube $\left(\mathrm{mm}^{2}\right)$ 


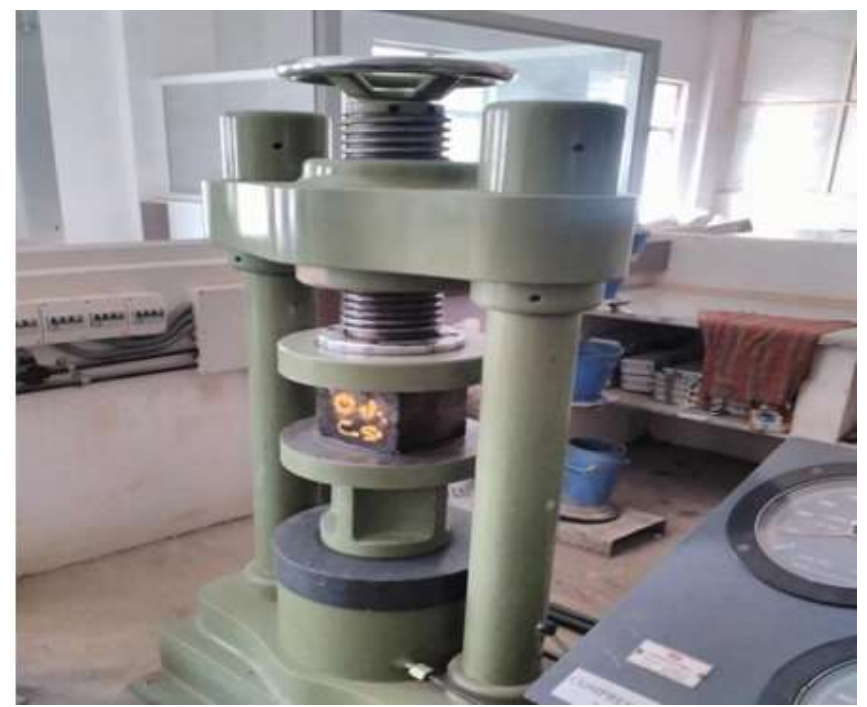

\begin{tabular}{|l|l|l|l|l|l|}
\hline Days & $\begin{array}{l}\mathbf{0} \% \\
\text { CS }\end{array}$ & $\begin{array}{l}\mathbf{1 5 \%} \\
\text { CS }\end{array}$ & $\begin{array}{l}\mathbf{3 0 \%} \\
\text { CS }\end{array}$ & $\begin{array}{l}\mathbf{1 5 \%} \text { CS } \\
\text { \& 20 \% } \\
\text { F.A }\end{array}$ & $\begin{array}{l}\mathbf{3 0} \% \\
\text { CS \& } \\
\mathbf{2 0} \% \\
\text { F.A }\end{array}$ \\
\hline $\mathbf{7}$ & 25 & 19.22 & 14.78 & 15.77 & 10.34 \\
\hline $\mathbf{2 8}$ & 32.44 & 28.88 & 23.98 & 26.67 & 21.22 \\
\hline $\mathbf{9 0}$ & 37.48 & 34.32 & 31.88 & 28.44 & 25.56 \\
\hline
\end{tabular}

From the above test results, it is clear that when coarse aggregate is substituted with CSA, the compressive strength is found to be reducing. This may be due to the fact that the failure of normal strength concrete is caused by bond failure of bonding $\mathrm{b} / \mathrm{n}$ Coconut shell aggregate and cement-mortar. Bonding between mortar and Coconut shell aggregate is weaker than that of Coarse aggregate. The decrease in strength was found to be high when replacement is done with coconut shell aggregate along with $20 \%$ Flyash.

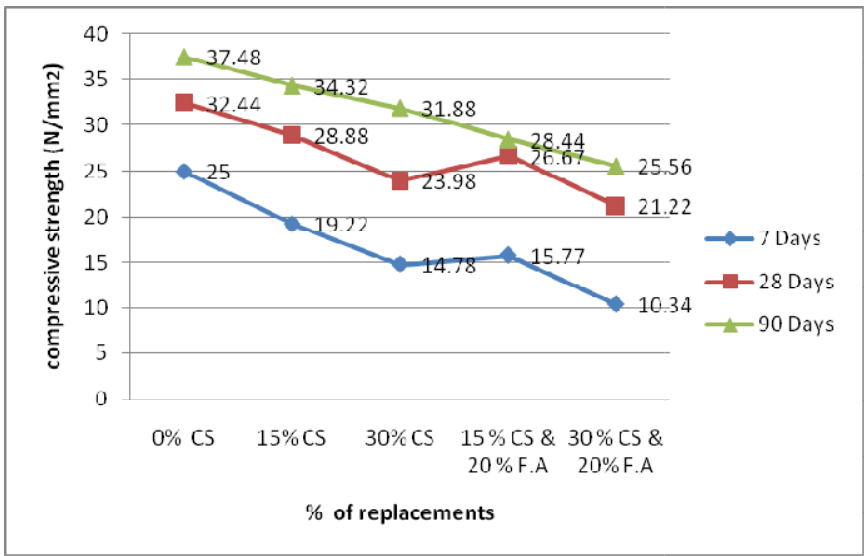

Graph: Showing that the variation of compressive strength with age for both (\%CS) and (\%CS+20\%flyash) replacement

\subsection{SPLIT TENSILE STRENGTH TEST:-}

This test was led on cylinders of size $150 \mathrm{~mm}$ distance across and $300 \mathrm{~mm}$ height. The testing of specimen ought to be completed at the earliest opportunity in the wake of curing. Specimen measurements were measured before the testing. Cleaned and cured specimens set in the testing machine. The platen was brought and was allowed down to touch the top surface of the specimen. The force was applied and increased continuously. Max. load at which the specimen failed was recorded and split tensile strength was calculated.

Formula to find out the split tensile strength : $\mathbf{F t}=$ 2P/pi LD

Where, $\mathrm{Ft}=$ tensile strength $(\mathrm{N} / \mathrm{mm} 2) \mathrm{P}=$ load at failure $(\mathrm{N})$

$\mathrm{L}=$ length of cylinder $(\mathrm{mm}) \mathrm{D}=$ diameter of cylinder

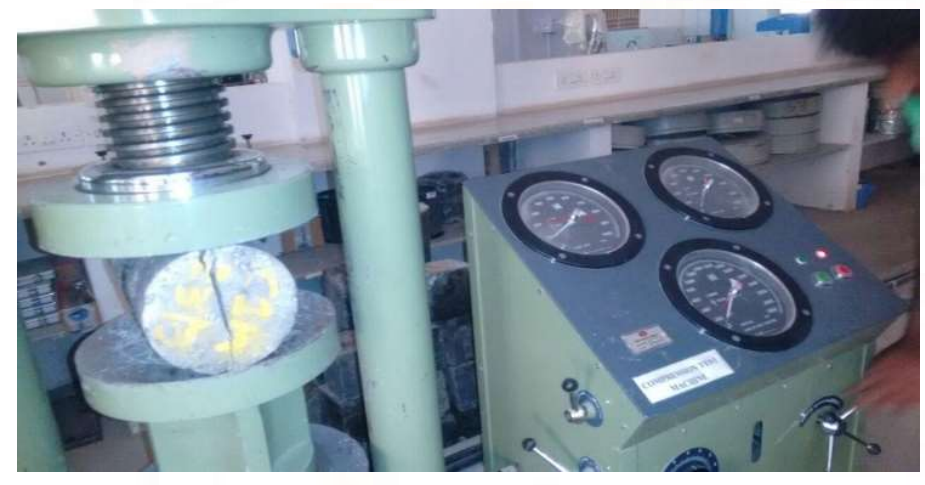

\begin{tabular}{|c|c|c|c|c|c|}
\hline days & $\mathbf{0} \%$ CS & $\begin{array}{c}15 \% \\
\text { CS }\end{array}$ & $\begin{array}{c}30 \% \\
\text { CS }\end{array}$ & $\begin{array}{c}\mathbf{1 5 \%} \text { CS } \\
\mathbf{2} 2 \% \\
\text { F.A }\end{array}$ & $\begin{array}{c}\mathbf{3 0} \% \\
\text { CS \& } \\
\mathbf{2 0} \% \\
\text { F.A }\end{array}$ \\
\hline $\mathbf{7}$ & 2.35 & 2.15 & 1.86 & 1.98 & 1.62 \\
\hline $\mathbf{2 8}$ & 3.56 & 3.32 & 2.69 & 2.93 & 2.26 \\
\hline $\mathbf{9 0}$ & 4.86 & 4.13 & 3.14 & 3.26 & 2.98 \\
\hline
\end{tabular}


International Journal of Trend in Scientific Research and Development (IJTSRD) ISSN: 2456-6470

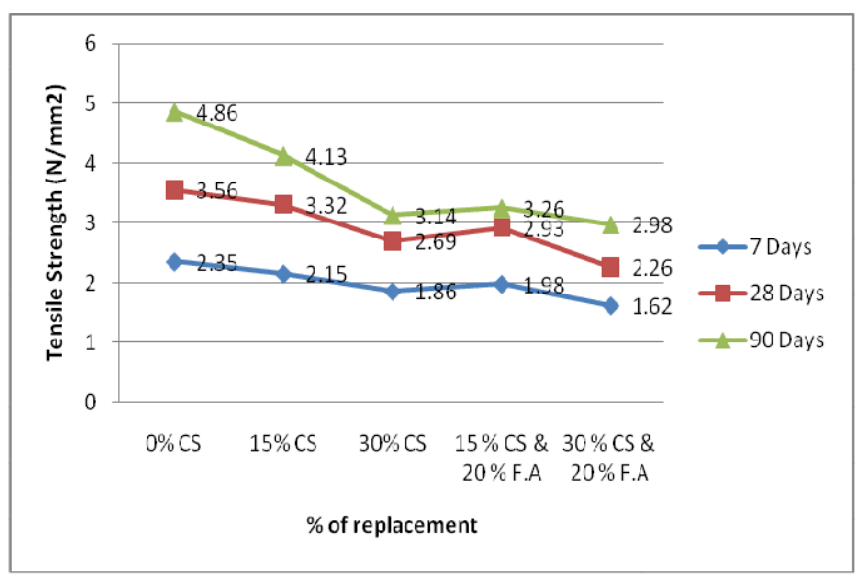

Graph: Showing that the variation of Tensile strength with age for both( $\% \mathrm{CS})$ and (\%CS+20\%flyash) replacement.

\subsection{FLEXURAL STRENGTH TEST ON PLAIN CEMENT CONCRETE}

For this test the beams of dimensions $100 \mathrm{mmX} 100 \mathrm{mmX} 500 \mathrm{~mm}$ were casted. Flexural quality otherwise called modulus of crack, modulus of rupture, or fracture quality. The flexural quality represents to the highest stress material experienced inside the material at its movement of rupture. The beam tests are observed to be trustworthy to quantify flexural quality. "Modulus of rupture" (MoR) is around $12 \%$ to $20 \%$ of compressive quality. Be that as it may, the best relationship of specific materials is gotten by research facility tests.

Flexural tests are more extremely sensitive to the specimen arrangement, handling, curing and setting in the machine for testing. a short time of drying in the shaft can deliver a sharp drop in the flexural quality of the specimen.

Equation to discover the flexural quality of concrete ;

$$
\mathbf{F b}=\mathbf{p l} /(\mathbf{b d} 2)
$$

Where;

$\mathrm{b}=$ measured width in $(\mathrm{m})$ of the specimen,

$\mathrm{d}=$ measured profundity in $(\mathrm{m})$ of the specimen at the point of failure,

$1=$ length in $(\mathrm{m})$ of the range on which the specimen was supported,

$\mathrm{p}=$ Max.load in $(\mathrm{kn})$ connected to the specimen.

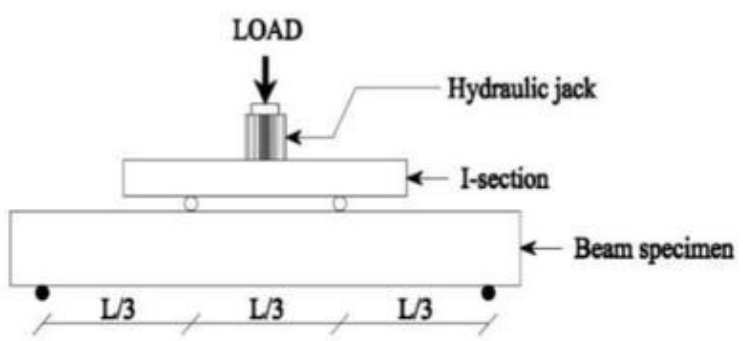

Flexural-Strength Test Results For 28 Days

\begin{tabular}{|l|l|l|}
\hline Days & $\mathbf{2 8}$ days & \\
\hline & $\begin{array}{l}\text { LOAD } \\
(\mathrm{Kn})\end{array}$ & $\begin{array}{l}\text { Strength } \\
(\mathrm{N} / \mathrm{mm} 2)\end{array}$ \\
\hline $\mathbf{0 \%}$ C.S & 24.35 & 9.74 \\
\hline $\mathbf{1 5 \%}$ C.S & 21.8 & 8.72 \\
\hline $\mathbf{3 0 \%}$ C.S & 16.8 & 6.72 \\
\hline $\mathbf{1 5 \%}$ C.S \& $20 \%$ F.A & 18.2 & 7.29 \\
\hline $\mathbf{3 0 \%}$ C.S \& 20 \% F.A & 14.4 & 5.76 \\
\hline
\end{tabular}

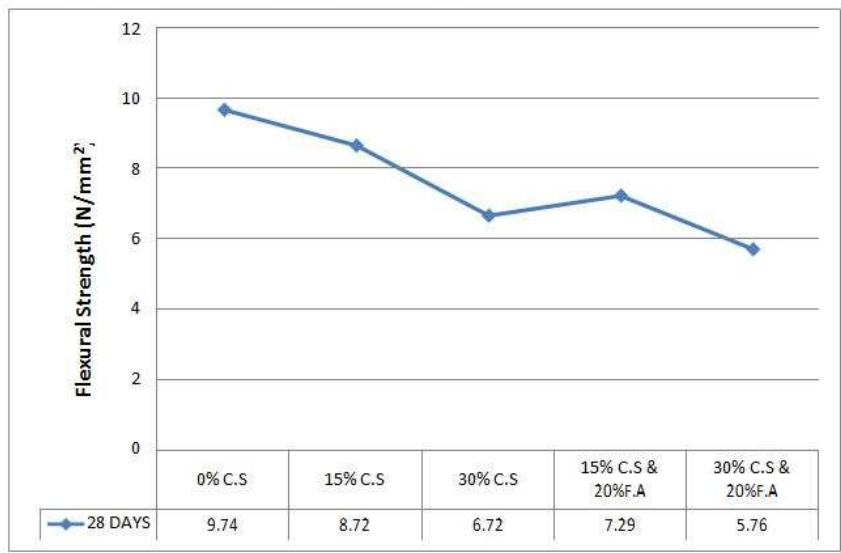

Graph: Showing that the variation of Flexural strength for 28 days for both (\%CS) and (\%CS+20\%flyash) replacement

\section{CONCLUSION AND FURTHER SCOPE}

\subsection{CONCLUSION:}

Utilizing more Replacement of coconut shells, It decreases the compressive, tensile and Flexural nature of concrete.

Increase in rate of C.S, decreases the densities of concrete. 
Increase in rate substitution by coconut shell builds workability of concrete.

Light weight concrete can be set up by utilizing coconut shells, as coarse aggregate.

When the different Percentage of CS as $15 \%$ and $30 \%$ is replaced in concrete with coarse aggregate. the compressive strength, split tensile strength, are more as compared to concrete replaced by coconut shell as $15 \%$ and $30 \%$ along with cement replaced by $20 \%$ fly ash.

Water absorption increases with increase in CS replacement.

\subsection{FURTHER SCOPE OF WORK:}

1. The study can be done with differing rate swap of the material for particular ease housing applications.

2. Building properties like water ingestion, diminishment in weight of cement and study on financial perspectives can be completed.

3. Impact of temperature on the concrete created can be contemplated.

4. Impact of various admixtures can be measured on CS concrete.

5. Durability considers on CS concrete ought to be done to evaluate its conduct in forceful situations.

\section{REFERENCES:}

1) Dewanshu Ahlawat, L.G.Kalurkar (2013), "Quality Properties of Coconut Shell Concrete", International Journal of Civil Engineering and Technology, vol 4, issue 6 Dec 2013

2) Kulkarni V.P, Kumar .S, (2013), "Relative study on coconut shell aggregate with conventional concrete", Vol.2, Issue 12, pp 67-70

3) Daniel Y.O, (2013), "Exploratory Assessment on Coconut Shell as aggregate in concrete", International Journal of Engineering Science Invention, Vol.2, Issue 5, pp 07-11

4) Amarnath Yeramala, Ramchandrudu.C, (2012), "Properties of concrete with coconut shell as aggregate substitution", International Journal of Engineering Inventions, Vol.1, Issue 6, pp 21-31
5) Experimental study of functionally graded beam with fly ash by K.Bajaj, Y.Shrivastava, P.Dhoke.

6) Compressive strength development of fly ash concrete for different replacement levels by B.K.Narendra.

7) Olanipekun, E,A, Olusola K.O. and Atia, O., (2006)“'Comparative study between palm kernel shell and coconut shell as coarse aggregate", Journal of Engineer and Applied Science, Asian Research Publishing Network. Japan, 2006.

8) R.Nagalakshmi, "Experimental Study on Strength Characteristics on M 25 Concrete with Partial Replacement of Cement with Fly Ash and Coarse Aggregate with Coconut Shell', International Journal of Science \& Engineering Research, 2013, Vol. 4, Issue 1.

9) K.Gunasekaran, "Usage of Coconut Shell as Coarse Aggregate in the Development of Light Concrete", Thesis- SRM University, 2011.

10) Beaure of Indian standards

11) IS $456: 2000$

12) IS $10262: 2009$

13) IS $383: 1970$ 